\title{
CADEIRA TASMIM: ASSENTO ERGONÔMICO VOLTADO PARA USUÁRIOS DA SALA DE DESENHO DO INSTITUTO FEDERAL DE MINAS GERAIS CAMPUS SANTA LUZIA
}

\author{
TASMIM CHAIR: SEAT ERGONOMIC BACK TO USERS OF THE DRAWING ROOM OF \\ THE FEDERAL INSTITUTE OF MINAS GERAIS CAMPUS SANTA LUZIA
}

\begin{abstract}
Thais Passos Quintão, Graduanda. Wemerton Luis Evangelista, D.Sc. Viviane Gomes Marçal, D. Sc.
\end{abstract}

(1) Instituto Federal de Educação, Ciência e Tecnologia de Minas Gerais e-mail: wemerton.evangelista@ifmg.edu.br

(2) Instituto Federal de Educação, Ciência e Tecnologia de Minas Gerais e-mail: thais.passos.tp.tp@gmail.com

\section{(3) Instituto Federal de Educação, Ciência e Tecnologia de Minas Gerais e-mail:gomesvivi@gmail.com}

Palavras-chave: Cadeira, Design, Ergonomia.

\begin{abstract}
Nas áreas de arquitetura, design, engenharia, entre outros, por mais que exista vários programas de desenhos assistidos por computador, ainda se faz presente a necessidade da valorização do desenho feito à mão, seja ele croquis ou desenhos técnicos. A partir disso, tem-se a necessidade da criação de um assento que possibilite a interação com a mesa de desenho que seja ergonômico, para amenizar os desconfortos que os alunos sentem durante a utilização da sala de desenho. Através da análise dos resultados dos questionários e entrevistas realizadas com os usuários da sala de desenho do IFMG campus Santa Luzia, foi possível conferir que, o assento presente na sala está inadequado. Diante disso, desenvolveu-se o modelo digital da cadeira Tasmim, com sistema de regulagem de altura e com encosto, a cadeira está adaptada às necessidades dos usuários e as atividades exercidas durante as aulas.
\end{abstract}

\section{Key-words : Chair, Design, Ergonomics}

In the areas of architecture, design, engineering, among others, even though there are several computer-aided design programs, there is still a need to value hand-drawn drawings, whether sketches or technical drawings. From this, it is necessary to create a seat that allows interaction with the drawing board that is ergonomic, to ease the discomforts that students feel during the use of the drawing room. Through the analysis of the results of the questionnaires and interviews with the users of the IFMG Santa Luzia drawing room, it was possible to verify that the seat in the room is inadequate. In view of this, the digital model of the Tasmim chair was developed, with a height adjustment system and with backrest, the chair is adapted to the users' needs and the activities carried out during the lessons. 


\section{$16^{\circ}$ \\ ERGODESIGN USIHC CINAHPA}

$16^{\circ}$ Ergodesign - Congresso Internacional de Ergonomia e Usabilidade de Interfaces Humano Tecnológica: Produto, Informações Ambientes Construídos e Transporte

$16^{\circ}$ USIHC - Congresso Internacional de Ergonomia e Usabilidade de Interfaces Humano Computador

CINAHPA | 2017 - Congresso Internacional de Ambientes Hipermídia para Aprendizagem.

\section{Introdução}

Segundo Moro (2005) o mobiliário escolar é de total influência no desempenho do aluno, durante a realização das atividades escolares. Esse mesmo mobiliário determina a postura que o usuário irá exercer durante a realização da tarefa, mas pelo fato de os estudantes passarem horas nessa mesma posição, caso o mobiliário esteja inadequado, irá causar desconfortos que podem desenvolver graves problemas anatômicos e físiológico no usuário.

Diante da valorização e da necessidade dos croquis e desenhos técnicos feitos a mão, ao efetuar a análise da atividade realizada na sala de desenho do Instituto Federal de Minas Gerais - Campus Santa Luzia, nota-se que há um incômodo diante ao conjunto integrado "mesa-assento" oferecido pela instituição. Diante dessas necessidades, foi desenvolvida a Cadeira Tasmim, que procura minimizar os problemas levantados durante a observação da atividade, aumentando o desempenho dos usuários e gerando conforto para os mesmos.

\section{Revisão Literária}

\subsection{Ergonomia e o estudo dos assentos}

No setor de mobiliário, a ergonomia é empregada na adequação da estrutura do móvel às medidas antropométricas do corpo do usuário, proporcionando conforto pelos materiais especificados para o conjunto, assim como por meio do desenho e forma do estofamento, dos apoios como encosto, apoio para braços, pés e etc.

Os assentos são mobiliários muito presentes no dia a dia das pessoas. Nos escritórios por exemplo, algumas pessoas chegam a passar 8 horas por dia sentadas, em frente aos computadores. Para isso, cada assento deve ser adaptado para o usuário,

ambiente de trabalho e integrar o conjunto "mesaassento". Assim, evitando desconforto, fadiga, estresse, dores e etc.

Para desenvolver o assento ergonômico delimitouse 6 princípios do assento, apresentados por Iida
(2005), para dar início aos estudos de variação de posturas. São eles:

1. As dimensões do assento devem ser adequadas às dimensões antropométricas do usuário.

2. O assento deve permitir a variação de postura.

3. O assento deve ter resistência, estabilidade e durabilidade.

4. Existe um assento adequado para cada tipo de função.

5. O encosto e o apoia braços deve ajudar no relaxamento.

6. Assento e mesa formam um conjunto integrado.

\subsection{A postura sentada}

Considerada a mais adequada para realização de atividades ligadas ao desenho, a postura sentada, de acordo com Andersson (1986) oferece algumas vantagens como: a diminuição de gastos energéticos, minimização da força exercida pelos membros inferiores, maior estabilidade durante a realização de tarefas, e redução da pressão hidrostática da circulação dos membros inferiores.

De acordo com Andersson (1975), além da postura, outro aspecto a ser analisado é o tempo em que o indivíduo passa sentado. Durante o decorrer do tempo em que o usuário estiver sentado é indicado mudar de postura com intervalos de 5 minutos para evitar dores e fadiga muscular. Além disso, permanecer por mais de 4 horas nessa posição favorece o desenvolvimento de dores lombares.

Segundo O'Sullivan e Kendell (2002), durante a execução da postura sentado, se não houver um apoio correto do posicionamento lombar, a pressão dos discos intervertebrais podem ter um aumento de $35 \%$.

\section{Metodologia}

Com objetivo de levantar possíveis problemáticas do assento da sala de desenho do Instituto Federal de Minas Gerais - Campus Santa Luzia, e baseado na metodologia de desenvolvimento de um novo 


\section{$16^{\circ}$ \\ ERGODESIGN USIHC CINAHPA}

$16^{\circ}$ Ergodesign - Congresso Internacional de Ergonomia e Usabilidade de Interfaces Humano Tecnológica: Produto, Informações Ambientes Construídos e Transporte

$16^{\circ}$ USIHC - Congresso Internacional de Ergonomia e Usabilidade de Interfaces Humano Computador

CINAHPA | 2017 - Congresso Internacional de Ambientes Hipermídia para Aprendizagem. produto descrita por Barroso (1982). foram realizadas pesquisas e análises de referenciais teóricos para obtenção de embasamento técnico e informativo para o desenvolvimento da cadeira Tasmim.

Ainda foram implantados questionários e entrevistas com os usuários desta sala de acordo com a diferenciação entre sexo e idade, em que os resultados seriam diretrizes para solucionar os problemas identificados, para que assim fosse criado e desenvolvido uma proposta de assento dentro das demandas analisadas através da metodologia qualitativa.

Também foram realizadas entrevistas com fisioterapelta e outros profissionais com o objetivo de identificar os problemas posturais presente nos usuários, diagnosticando e instruindo sobre as condições corretas de execução da atividade na postura sentada.

Em seguida, foram realizadas pesquisas sobre ofertas tecnológicas. Analisou-se cuidadosamente todos os mecanismos, tecnologias e materiais disponíveis no mercado, para que assim pudesse determinar os funcionamentos primordiais do novo assento.

Dando continuidade ao desenvolvimento do produto, determinou-se então os objetivos, conceito e inspirações, para dar introdução ao desenvolvimento do design do novo assento a partir da análise do público alvo. Essa análise foi realizada através de observação e pesquisas relacionadas aos usuários de mobiliário para desenho. A partir disso, foram desenvolvidos croquis para aumentar as possibilidades de estudos para a forma, dimensões antropométricas e funcionamento do assento.

Sob esse aspecto, a partir de todas essas demandas, e decisões tomadas, iniciou-se então os testes de funcionamento da cadeira por meio da criação de um protótipo para que futuramente possa ser realizada a confecção do assento utilizando ferramentas e processos da confecção em marcenaria.

\section{Análise de resultados}

Após a aplicação do questionário para os alunos, com o objetivo de realizar o levantamento de dados, obteve-se o seguinte resultado em relação ao atual assento da sala de desenho.

Cerca de $86 \%$ dos alunos estão insatisfeitos com o conforto do assento. Além disso, a ausência de espaço para colocar os materiais utilizados faz com que o usuário tenha que se movimentar com maior frequência para alcançá-los, assim adotando posturas inadequadas que podem resultar em lesões e dores musculares. Esse fator de desconforto, de acordo com Look (2007) torna o mobiliário inadequado.

Também foi possível analisar que $100 \%$ dos usuários da sala de desenho se inclinam para realizar as atividades, fazendo com que a variação de postura seja frequente. Além disso, já com queixas de dores nas costas devido à má postura, 57\% dos usuários, afirmam ser necessário a presença de encosto para as costas no assento.

De acordo com Campelo (2016), a pressão do dia a dia, acaba fazendo com que as pessoas executem posições que podem gerar problemas de saúde. Segundo ele, são diversas as formas de problemas que podem aparecer a longo prazo "Escoliose, trombofilia, hérnia de disco, artrose, espondilose, dentre outros, que devido a pouca prática de exercícios, e consequentemente à obesidade dos usuários, podem aparecer ou se agravar". Campelo (2016) ainda acrescenta que para que esses problemas não aconteçam, é necessário manter bons hábitos, entre eles a atividade física, e fazer uso de mobiliários mais adequados à atividade e ao usuário.

De acordo com as entrevistas aplicadas e médias geradas baseadas nas medidas interpessoais dos alunos da sala de desenho, o assento produzido deve suportar o peso mínimo de $93 \mathrm{~kg}$, já que o valor máximo do peso entre os homens que usam a sala de desenho, e não possuem obesidade, é de 93 $\mathrm{kg}$. Visto que, para ser mais confortável e adequado ao usuário, $\mathrm{o}$ assento deve ter regulagem de altura, concluindo que a altura do assento deve variar dentro de 45 a $60 \mathrm{~cm}$. 


\section{$16^{\circ}$ \\ ERGODESIGN USIHC CINAHPA}

$16^{\circ}$ Ergodesign - Congresso Internacional de Ergonomia e Usabilidade de Interfaces Humano Tecnológica: Produto, Informações Ambientes Construídos e Transporte

$16^{\circ}$ USIHC - Congresso Internacional de Ergonomia e Usabilidade de Interfaces Humano Computador

CINAHPA | 2017 - Congresso Internacional de Ambientes Hipermídia para Aprendizagem.
O encosto deve atender a altura máxima de $35 \mathrm{~cm}$ que equivale a média da altura da região lombar dos usuários. Além disso, diante das respostas do questionário e do levantamento de dados antropométricos concluiu-se que, o atual assento da sala de desenho não possui apoio para os pés nem para os braços.

$\mathrm{O}$ apoio de braços, para um assento que compõe o conjunto "mesa-assento" da sala de desenho, não é necessário. Nesse caso, o apoia braços iria diminuir as possibilidades de regulagem da inclinação da mesa, causando maiores desconfortos e forçando o usuário a adotar posturas inadequadas durante a realização de atividades. Já o apoio para os pés se faz necessários, devido ao fato de oferecer maior variação de posturas adequadas para o aluno.

Campelo (2016) afirma que ninguém consegue manter a mesma posição por $6 / 8$ horas. Por isso optou-se pela implantação do apoio para os pés na cadeira. Diante dessa necessidade, o apoio para os pés deve atender o tamanho máximo do comprimento dos pés dos homens, que na tabela de levantamento antropométricos é equivalente a 25 $\mathrm{cm}$.

\subsection{Desenvolvimento do assento}

A partir desses dados e análises, iniciou-se então o processo de desenvolvimento físico do protótipo. Após o estudo dos materiais, analisando fatores como: durabilidade, impactos ambientais, gastos de energia e importância conceitual, optou-se pela utilização da madeira.

De acordo com Batista (2016), a madeira possui durabilidade maior que de outros materiais como alumínios e polímeros, dessa forma a manutenção ocorre após muitos anos de uso. Ele ainda acrescenta que a madeira oferece maior segurança ao usuário, visto que ela não oxida, e na própria natureza já desempenha funções estruturais de sustentação de árvores de grande porte e de muitos anos. Além disso, nos cursos técnicos e de graduação no Brasil, não há a valorização do estudo de estruturas em madeira.
Com tantas ofertas tecnológicas utilizadas no dia a dia, a utilização da madeira foi se tornando cada vez menor, esse fato tem aspectos positivos e negativos. A vantagem é a conservação da flora brasileira que já sofreu grandes proporções no quesito de desmatamento. A desvantagem é que os aspectos vernaculares da arquitetura foram deixados de lado e juntamente com essa tecnologia de processamento que existe hoje, proporciona maior diversidade de produtos e requinte no design e acabamento dos móveis, tornando-os ainda mais duráveis e resistentes a impactos e umidade.

A madeira ainda tem ótimos fatores que colaboram para o conforto térmico do mobiliário. As fibras com baixa condutividade de calor ou frio fazem com que a temperatura da madeira seja estável, ou seja próxima à temperatura ambiente.

Dentro do amplo catálogo de madeiras, foi escolhida a madeira de ipê e o compensado de Freijó. O Ipê é uma madeira nativa, mais especificamente o ipê do Cerrado (utilizado para a fabricação da estrutura do assento), é cultivado em Minas Gerais, esse fato faz com que o tempo de transporte desse material em automóveis seja inferior quando comparado ao transporte de materiais vindo de outros estados como por exemplo Bahia, Amazônia. De acordo com Young (1993) os veículos de transportes automotivos, são responsáveis por 30,7\% de emissão de CO2. Dessa forma ao utilizar um recurso regional o índice de emissão de $\mathrm{CO} 2$ se torna inferior.

O compensado é uma madeira reflorestada devido a suas lâminas serem feitas de Pinus. $\mathrm{O}$ compensado de freijó não é nada mais que, lâminas de pinus revestidas por uma fina lâmina de freijó, responsável pelo conforto e acabamento do assento, trazendo um design jovial a cadeira, através do contraste criado com a tonalidade do ipê, dessa forma, fazendo menção ao conceito do novo assento que é: durável, confortável, regulável e jovial.

O Jeans, utilizado para revestir o estofamento, proporciona um design aconchegante ao mobiliário, devido a relação visual que se faz às calças jeans que são muito utilizadas e consideradas confortáveis pelas pessoas. Ele é um
Realização:

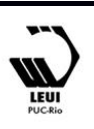




\section{$16^{\circ}$ \\ ERGODESIGN USIHC CINAHPA}

$16^{\circ}$ Ergodesign - Congresso Internacional de Ergonomia e Usabilidade de Interfaces Humano Tecnológica: Produto, Informações Ambientes Construídos e Transporte

$16^{\circ}$ USIHC - Congresso Internacional de Ergonomia e Usabilidade de Interfaces Humano Computador

CINAHPA | 2017 - Congresso Internacional de Ambientes Hipermídia para Aprendizagem. tecido prático, impactante e atemporal. Por ser um mobiliário escolar, a cadeira será utilizada por muitas pessoas, e acumula sujeira, dessa forma pensou-se no Jeans devido ao fato de permitir a aplicação de produtos de impermeabilização, facilitando a limpeza. Ao contrário do que muitos pensam, o Jeans não concentra calor, ele apenas se adapta a temperatura corporal do usuário. Além disso, é um produto de baixo custo.

Por fim, o sistema giratório da cadeira faz com que a postura do usuário permaneça diante $o$ movimento de rotação ajudando no alcance de materiais, evitando inclinações corporais incorretas que possam causar dores e lesões posteriores.

\section{A Cadeira Tasmim}

A cadeira Tasmim, representada nas figuras $01 \mathrm{e}$ 02, possui nome de origem Egípcia derivado da língua árabe, que significa "desenho", a cadeira possibilita a variação de postura, e induz o aluno a manter posturas mais adequadas através da adoção do encosto para a região lombar, e dos apoios para os pés embutido na estrutura do assento. Além disso, esse assento possibilita a regulagem da altura, e integra completamente o conjunto "mesaassento", adequando assim o espaço de trabalho ao usuário desse ambiente, aumentando a produtividade do usuário na realização das atividades, oferecendo mais conforto, e disponibilizando recursos que irão ajudar na diminuição dos problemas de saúde relacionados ao DORT (Distúrbio Osteomuscular Relacionado ao Trabalho).

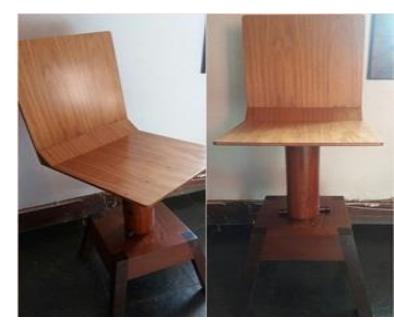

Figura 01: Fotos Cadeira Tasmim.

Estrutura em madeira. Fonte: Autores (2017).

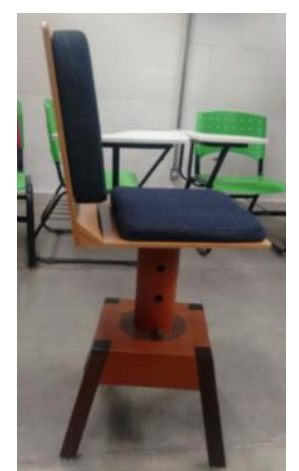

Figura 02: Cadeira Tasmim Finalizada. Fonte: Autores (2017).

\section{Referências Bibliográficas}

\section{BATISTA, Jatil. Propriedades, vantagens e desvantagens do uso da madeira. Entrevista. Belo Horizonte. 2016.}

\section{CAMPELO, Marcone. Os problemas causados} pela má postura. Entrevista. Belo Horizonte. 2016.

FILHO, Eduardo Romero. Projeto do produto. Apostila do curso. $8^{\circ}$ ed. Universidade Federal de Minas Gerais, Escola de engenharia. Departamento de Engenharia de produção. Belo Horizonte, 2006.

FRAINER, Deivis Elton Schlickmann et al. Padronização e confiabilidade das medidas antropométricas para pesquisa populacional. Disponível em:

<http://migre.me/uGCeN>. Acesso em: $07 \mathrm{de}$ fevereiro de 2017

FRANZOSA, Richard G., 1992, "CAPP: Manufacturing Data Management for Concurrent Engineering". In: AUTOFACT, Conference Proceedings 1992. Publ by SME, Publisher, Manufacturing Engineering, Dearborn, MI, USA. p 22-13-30.

GERHARDT, Tatiana Engel (Org.); SILVEIRA, Denise Tolfo (Org). Métodos de pesquisa. Porto Alegre: Editora da UFRGS, 2009. Disponível em: <http://www.ufrgs.br/cursopgdr/downloadsSerie/d erad005.pdf $>$. Acesso em: 
$16^{\circ}$ USIHC - Congresso Internacional de Ergonomia e Usabilidade de CINAHPA Interfaces Humano Computador

CINAHPA | 2017 - Congresso Internacional de Ambientes Hipermídia para Aprendizagem.

IIDA, Itiro. Ergonomia projeto e produção. $2^{\circ}$ ed. Revista e ampliada. Editora: Edgard Blücher. São Paulo, 2005.

MARQUES, Nise Ribeiro; HALLAL, Camilla Zanfolini; GONÇALVES, Mauro. Características biomecânicas, ergonômicas, e clínicas da postura sentada: uma revisão. Fisioterapia e pesquisa, São Paulo. Vol.17 n³, p. 270 - 6. 2010.

MORESI, Eduardo. Metodologia da pesquisa. Disponível em: <http://migre.me/uGBnD>. Acesso em: Março de 2003.
PEQUINI, Suzi Maranhão. Ergonomia aplicada ao Design de produtos: um estudo de caso sobre o Design de bicicleta. FAU-USP, 2005.

STERN, P.C., YOUNG, O.R \& DRUCKMAN, D. (orgs.). 1993. Mudanças e agressões ao meio ambiente. Makron Books. São Paulo. 314 p

\section{Agradecimentos}

Aos estudantes dos cursos de Design de Interiores, Engenharia Civil, Arquitetura e Edificações, pela colaboração durante as entrevistas e aplicação de questionários. Ao Laboratório de Ergonomia e Segurança do IFMG - Campus Santa Luzia. 